\title{
EFL Learner's Thinking in Argumentative Writing
}

\author{
Betharia br. Sembiring Pandia ${ }^{1,{ }^{*}}$ Berlin Sibarani ${ }^{1}$
}

\author{
${ }^{1}$ Universitas Negeri Medan \\ Corresponding author.Email. bethariasembiring@gmail.com
}

\begin{abstract}
The objective of this study was to describe the EFL learners' thinking in writing argumentative text. The topic of their writing was determined entitled of Should social media be banned?. The EFL learners' thinking was based on the existence of logic of argumentation proposed by Toulmin, they are: claim, reason, warrant, and backing. This study revealed that the subjects from three grade levels or semester did not show any significant difference in their logic of argumentation. They tended to use personal opinion to persuade readers rather than present factual supports in their reasons. The subjects' similar elements of argumentative writing across all groups, the second, fourth, and sixth semester, might be majorly due to low language mastery. It could be seen that there were a lot of errors in terms of grammar or sentence structure.
\end{abstract}

Keywords: Argumentative writing, EFL, Thinking

\section{INTRODUCTION}

Writing is seen in two perspectives; it is both social and cognitive activity [1]. As a social activity, writing pertains to reader-oriented, emphasizing the aim of writing; it may be persuading, informing, and explaining something to readers. As cognitive activity, writing is writer-oriented. It means that writer's ideas along with its organization are centralized in the writer's mentality. Writer's aim and the organization of the ideas are conveyed with language. It deals with the word choices and grammar. From this point, it is concluded that language mastery of the writer determines the clarity of the ideas as well as the accomplishment of the goal.

Besides language mastery, the other factor that determines writing quality is the thinking or logic of the ideas. Logic in writing refers to the point the author is trying to make, isolating the proportions asserted, and identifying their relationship [2].

EFL learners with different level of mastery of English will face different problems in conveying the idea as the results of their thinking. Good thinking with a low level of English mastery may produce different writing quality from those with bad thinking with a high level of English mastery and those with good thinking and high level of English mastery. In relation to writing argumentative text, the students may not be able to convince their readers if they are lack of language mastery and awareness of content area (thinking).
This article presented the integration between thinking and language mastery in producing argumentative writing in EFL context.

Argumentative writing is a product of the writer's inquiry and critical thinking. Inquiry in argumentative writing refers to the situation in which the writers question about a topic, seek its various views and compare it to their knowledge [3]. In addition to the inquiry, in order to be successful in expressing argument, critical thinking is required. Its role in writing argumentation is to make the writer decide the focus of the problem, decide what supports and details are linked to the writer's claim, and what opposing view that needs anticipating. This is also emphasized by Mcquade and Atwan who state that making well-constructed claims in argumentative writing is the indicators of cognitive and verbal achievement [4]. Thus, writing argumentative text is closely related to talking about thinking.

The study of argumentative writing in relation to thinking was conducted. Pei, Zheng, Zhang \& Liu studied about critical thinking and argumentative writing among EFL learners in China [5]. They claimed that critical thinking was crucial to show the quality of argumentative writing. Their study found that the students with high critical thinking skills provided relevant support, clear and logical support to their arguments. However, it was not mentioned how they judged certain students as critical thinkers and had better quality in writing argumentative text. This 
missing part can be understood in the previous research, preceding Zhang \& Liu, that was a research conducted by [6]. They stated that critical thinking can be trained by having discussions and subsequent writing. The group discussions involve the activities like group reflections on suggested topics, training in close reading of the topic in question to identify the focus, the flow of the ideas in order to make them involved in writing task, drafting and finalizing the writing task which peers and teachers can discuss. Subsequent training in writing could be given to students as they go to the higher grade. Based on this idea, it can be concluded that thinking is aware of what is being thought until someone reaches a deep understanding of it.

A logical argumentation is the integration of its elements such as: claim, reason, ground (data), warrants and backing. [7]. Each of the element can be understood as in this following explanation:

a. Claim: the precise standpoint of the writer towards the topic.

b. Reason : the rational motive for the claim.

c. Grounds/Data: the supports needed to make claim and reason logical. It can comprise of statistics, causal links, testimony, examples, or anecdotes.

d. Warrant : the underlying assumption that forms the enthymeme (claim and reason) into a complete logical structure.

e. Backing: supporting the warrant and persuading the audience/readers to accept the warrant.

\section{METHODS}

This study employed descriptive qualitative design. There were three groups of undergraduate students assigned to write argumentative text; they were the $2^{\text {nd }}$, $4^{\text {th }}$, and $6^{\text {th }}$ students. There were 30 students from each grade/ semester. They were chosen as the subjects of the study because they had studied writing in every semester and it was assumed that higher grade students would write better. The topics were Should social media be banned? However, there were not all subjects' writing were presented in this article; there were only the data representation. The data was taken based on the theory of [8], they were: data condensation, data display, and drawing conclusion/verification. Data condensation is defined as the process of selecting, focusing, simplifying, abstracting, and transforming. This process is meant to enable the researcher to display the data or to draw a conclusion. The subject's writing which totals up to 180 pieces were identified and selected.

\section{RESULTS AND DISCUSSION}

The data of this study were the sentences that represented the elements of argumentation such as claim, reason, ground/data, warrant, and backing in which these elements were proposed by Toulmin [7]. However, this study only claimed, reason, and ground/data found as the data.

\subsection{The Analysis of the Argumentation Written by the $2^{\text {nd }}$ Semester Students}

\section{Data 1}

Claim :

To become outstanding will lead teens to use social media excessively.

Reasons :

First, social media has allowed them to take their lives online from when they wake up till they get back to sleep via their smartphone...

Second, social media could decrease their real life social interaction because they are being comfortable with their online friends...

Third, by using social media, teens will more look at the screen of their smartphone...

Based on data 1, it was shown that the firstsemester students only presented two elements in their argumentative writing, they were: claim and reasons. The claim was written in the last sentence of the first paragraph. In the next paragraphs, the subjects provided reasons for their claims. However, there were some problems in the idea development for each reason. The first problem was the subjects' grammar knowledge. It was seen from the way the subjects use words to form sentences. They were written in the wong grammar. The second, every reason was not well-developed as data or facts did not support it; it was just the personal opinion of the writer as it could be seen in this paragraph of reason: "...it will ruin their sleep pattern at night. It can increase their risk of exhaustion. They will not focus on their study at school. It is because they have to online anytime." From these sentences, the third problem was revealed. It was the problem of cojoining sentences. The writer did not use any cohesive devices to join the sentences.

\subsection{The Analysis of the Argumentation Written by the $4^{\text {th }}$ Semester Students}

Data 2

Claim :

Therefore, I do agree that social media should be banned for students at Junior High School

Reasons :

Firstly, social media make people do the crime easily. For example: "Audrey case". We can see that 
the case happened because of bullying in social media...

Secondly, social media make students become wasting of money. When they want to access their social media, such as Facebook, Instagram, Whatsapp, etc. It means that they should buy the "Paket Internet" for browsing their social media. They cannot save their money.

Thirdly, social media make students become addicted. They will play with their social media on and on. They will waste their time and they cannot manage their time well. They will be lazy to study because they prefer to play social media. They are also lazy to hard think to do their homework or assignments because they can copy-paste the answer easily from the internet.

Based on data 2, it could be concluded that the subjects tried to address their writing to a specific prospective reader, the Junior High School students. Besides, it could be seen that the claim was stated implicitly and it was in line with the reasons. However, the reasons were not supported with adequate data. In the first reason, the subject tried to provide a factual support by taking the bullying case "Audrey" at that time. But, the case was not elaborated and was not clearly linked to the claim. It might be hard for readers to understand the reason if they did not have any information about the bullying case. In the next reasons, the existence of factual support was not even indicated.

\subsection{The Analysis of the Argumentation Written by the $6^{\text {th }}$ Semester Students}

\section{Data 3}

Claim :

This habit that is using social media seriously lead the teens to some bad effects.

Reasons :

First, most teens stay connected to the internet, accessing social media the whole time. They always check their social media on the smartphone. From the time they wake up in the morning till they back to sleep at night. They usually stayed up the whole night. This habit could ruin their sleep pattern and it would lead to a higher risk of exhaustion and depression, It can affect their performance at school.

Second, social media could decrease the real life social interaction because they are being more comfortable with their online friends.

Based on data 3, the subjects generalized that their prospective readers were teenagers. For the supports, the subjects might argue based on their own personal experience as teenagers. In the first reason, the subjects wanted to tell readers that social media could badly affect students' focus at school. Although statistical data or facts were not provided, the relationship between social media and students' focus were briefly stated. However, inconsistency was found in the second reason. The subject did not elaborate on the relationship between social media and real life social interaction.

\section{CONCLUSION}

Regarding to EFL learner's thinking in argumentative writing, it could be concluded that most of them focused on their claim, but they did not provide adequate factual support; they presented their personal experience to support their claim. By referring to this point, it could be inferred that writers' personal opinion or experience was enough to convince the readers.

In relation to the higher class (semester) students, language mastery did not always go in the same way with their thinking; one group of subjects might be in the higher class than the other one but it did not guarantee that they had a higher level of thinking in writing argumentative text.

\section{ACKNOWLEDGMENTS}

I would like to express my gratitude to the undergraduate students for taking up their time to finish this article.

\section{REFERENCES}

[1] K. Hyland, Teaching and researching writing. Routledge, 2015.

[2] D. Kelley, The art of reasoning: An introduction to logic and critical thinking. WW Norton \& Company, 2013.

[3] J. D. Ramage, Writing Arguments: A Rhetoric with Readings, Books a la Carte Edition, Mla Update Edition. Prentice-Hall, 2016.

[4] D. McQuade, Thinking in Writing. New York: Alfred a Knopf Inc, 1983

[5] Z. Pei, C. Zheng, M. Zhang, and F. Liu, "Critical Thinking and Argumentative Writing: Inspecting the Association among EFL Learners in China.," English Lang. Teach., vol. 10, no. 10, pp. 31-42, 2017.

[6] S. R. Mehta and R. Al-Mahroogi, "Can thinking be taught," Link. Crit., 2014.

[7] S. E. Toulmin, The uses of argument. Cambridge university press, 2003.

[8] M. B. Miles, A. M. Huberman, and J. Saldana, "Qualitative Data Analysis (H. Salmon Ed," Calif. Arizona State Univ. USA, 2014. 